\title{
Influence of depression on the executive functioning of patients with advanced idiopathic Parkinson's disease without dementia.
}

Hurtado-González $\mathrm{CA}^{1,2^{*}}$, De la Cruz-Cifuentes $\mathrm{O}^{3}$, Triviño $\mathrm{O}^{3}$, Rinco $\mathrm{A}^{3}$, Seminec $\mathrm{D}^{4}$, De la CruzCifuentes $\mathrm{G}^{5}$, Olayo BRI ${ }^{3,6}$

${ }^{1}$ School of Psychology, Coperativa University of Colombia in Cali, Cali Branch Campus, Colombia

${ }^{2}$ Center for Evaluation and Functional Neuro-Rehabilitation for Patients with Parkinson's Disease, Salamanca, Spain

${ }^{3}$ School of Medicine, Libre University Cali, Colombia

${ }^{4}$ Faculty of Psychology, Research Group Basic and Applied Clinical Neurosciences, Cooperative University of Colombia, Colombia

${ }^{5}$ Watson Clinic, Urgent Care Family Practice, Florida, USA

${ }^{6}$ Instiute of Biomedical Research, School of Medicine Free University, Cail, Colombia

Keywords: Depression, Executive functioning, Parkinson's disease.

Accepted on January 31, 2018

\section{Introduction}

Parkinson's disease (PD) is a neurodegenerative disease characterized by symptoms such as bradykinesia, stiffness, instability and postural tremor [1]. It affects the basic, instrumental and advanced activities of daily life, affecting the deterioration of individual, social and family life quality [2-5].

\section{Objective}

To study the influence of depression on executive functioning in patients with advanced idiopathic and non-dementia
Parkinson's disease (IPDD) at Hoehn and Yahr III and IV stages [6].

\section{Participants}

50 subjects (34 men, 16 women) diagnosed with IPDD, in stages III and IV of the Hoehn and Yahr scale, and 50 healthy subjects (20 men, 30 women) without cognitive impairment of similar socio-demographic characteristics (Table 1).

Table 1. Difference of means. Group of subjects with PE and comparison group.

\begin{tabular}{|c|c|c|c|c|c|c|}
\hline \multirow{2}{*}{ Variables } & & \multirow{2}{*}{ Group with PD } & \multirow{2}{*}{ Comparison group } & \multicolumn{3}{|l|}{ Contrast test } \\
\hline & & & & Value & g. I. & P-sig \\
\hline \multirow{3}{*}{ Age } & & $64.86 \pm 6.53$ & $53.75 \pm 8.49$ & \multirow{3}{*}{$\mathrm{T}=7.28$} & \multirow{3}{*}{96} & \multirow{3}{*}{$0.000^{* *}$} \\
\hline & & IC 95\%: 63.00-66.72 & IC 95\%: 51.28-56.22 & & & \\
\hline & & Rank: 47-75 (Median: 65.5) & Rank: 45-75 (Median: 52.0) & & & \\
\hline \multirow{2}{*}{ Gender } & Males & $66.0 \%(33)$ & $39.6 \%(20)$ & \multirow{2}{*}{$\mathrm{Chi}^{2}=6.86$} & \multirow{2}{*}{1} & \multirow{2}{*}{$0.009^{\star \star}$} \\
\hline & Women & $34.0 \%(17)$ & $60.4 \%(30)$ & & & \\
\hline \multirow{4}{*}{ Civil status } & Married & $88.0 \%(43)$ & $83.3 \%(41)$ & \multirow{4}{*}{$\mathrm{Chi}^{2}=6.92$} & \multirow{4}{*}{3} & \multirow{4}{*}{$0.075^{\mathrm{NS}}$} \\
\hline & Single & $4.0 \%(3)$ & $8.3 \%(5)$ & & & \\
\hline & Widowers & $8.0 \%(4)$ & $2.1 \%(2)$ & & & \\
\hline & Divorced & $0 \%(-)$ & $6.3 \%(2)$ & & & \\
\hline Stairway & Basi studies & $68.0 \%(36)$ & $35.4 \%(18)$ & $\mathrm{Chi}^{2}=12.01$ & 2 & $0.002^{* *}$ \\
\hline
\end{tabular}




\begin{tabular}{lll}
\hline Middle studies & $22.0 \%(12)$ & $31.3 \%(15)$ \\
\hline High studies & $10.0 \%(2)$ & $33.3 \%(17)$
\end{tabular}

Note: ${ }^{* *}$ Significant at $1 \%$; PD: Parkinson's Disease; NS: Not Significant.

\section{Inclusion criteria}

Group 1: Diagnosis of Parkinson's disease is performed by a specialist in Neurology; stages III and IV of the Hoehn and Yahr scale [6]; no dementia: score in the Mini Mental Parkinson-MMP, a score equal to or greater than 27 and in the Dementia Rating Scale a score equal to or greater than 130 $[7,8]$; not present less than ten years of evolution of the illness; do not present a history of clinically demonstrable neurological, neuropsychological and/or psychopathological alterations; do not present a history of alcohol abuse and/or toxic substances; subjects should not have undergone any kind of functional neurosurgery for the treatment of Parkinson's disease; "Age between 45 and $80 \mathrm{y}$; to present a level of education of at least 6 years.

Group 2: Same criteria as Group 1, except for the diagnosis of Parkinson's disease.

\section{Material}

Yesavage Depression Scale (IDSS) [9]; executive functions: "Initiation/Perseveration of the Dementia Rating Scale DRS [8]"; "Motor Planning, Semantic Verbal Fluency and Task Change of the SCOPA-COG" [10]; and "Alternating Verbal Fluency and Action of Parkinson's Disease Cognitive Rating Scale-PD-CRS" [11].

\section{Process}

From clinical history, clinical and neurological data of interest were obtained. If the subject fulfilled the criteria to be part of the study, an evaluation was made with the tests discussed above.

\section{Statistical analysis}

Mean difference, student T, Mann-Whitney U-test, Spearman's Rho.

\section{Results}

There were statistically significant differences between patients with IPDD and the comparison group $(\mathrm{p}<0.000)$ (Table 2$)$ in all executive functioning components evaluated. Significant differences were also found between the two groups in the total score obtained on the scale of Yesavage $(p<0.01$ and Table 2) [9].

Table 2. Mann-Whitney U-test.

\begin{tabular}{lll}
\hline IDSS & $\mathbf{p}$ \\
\hline Initiation-perseverance (Mattis) & 29.00 & 0.001 \\
\hline
\end{tabular}

\begin{tabular}{lll}
\hline Motor planning (Mattis) & 26.43 & 0.001 \\
\hline Verbal fluency semantic (Scopa-Cog) & 28.32 & 0.001 \\
\hline Task change (Scopa-Cog) & 27.41 & 0.001 \\
\hline Alternating verbal fluency (PDCRS) & 28.12 & 0.001 \\
\hline
\end{tabular}

There is a statistically significant negative correlation between the total score obtained on the Yesavage scale and the scores obtained in the tasks of semantic verbal fluency $(\mathrm{rho}=-0.248$; $\mathrm{p}=0.047)$ and task change of SCOPA-COG ( $\mathrm{rho}=-0.314$; $\mathrm{p}=0.001$ ) (Table 3) [10].

Table 3. Spearman's Rho.

\begin{tabular}{lll}
\hline Measurement instrument Rho & p \\
\hline Verbal fluency (Scopa-Cog) & -0.248 & 0.047 \\
\hline Task change (Scopa-Cog) & -0.314 & 0.001 \\
\hline
\end{tabular}

\section{Conclusion}

Subjects with IPDD in stages III and IV of the Hoehn and Yahr scale have higher depressive symptoms than the normal group of subjects.

The presence of depressive symptomatology in patients with IPDD correlates negatively with performance in executive functioning tasks, specifically in semantic verbal fluency tasks and SCOPA-COG task change.

Depressive symptomatology influences the executive functioning of subjects diagnosed with IPDD, which may be clinically related to dysfunction fronto subcortical and dorsolateral cortex circuits, brain structures that correlate with neurobehavioral disorders such as depression.

It is suggested to generate functional neurorehabilitation plans, which aim to improve the quality of life in people with this type of diagnosis.

For the field of neurosciences, and for us neuroscientists, Parkinson's disease continues to be a dilemma from its etiology to its treatment, but this does not stop us from continuing to investigate different practices and experiments that lead to the slowing down of the disease, and of course to the improvement of their quality of life.

\section{References}

1. Bonnet AM, Czernecki V. Non-motor symptoms in Parkinson's disease: cognition and behavior. Geriatr Psychol Neuropsychiatr Vieil 2013; 11: 295-304. 


\section{dementia}

2. Samii A, Nutt JG, Ransom BR. Parkinson's disease. Lancet 2004; 363: 1783-1793.

3. Quelhas R, Costa M. Anxiety, depression, and quality of life in Parkinson's disease. J Neuropsychiatr Clin Neurosci 2009; 21: 413-419.

4. Polletti M, De Rosa A, Bonuccelli U. Affective symptoms and cognitive functions in Parkinson's disease. J Neurol Sci 2012; 317: 97-102.

5. Zesiewicz TA, Hauser RA. Depression in Parkinson's disease. Curr Psychiatr Rep 2002; 4: 69-73.

6. Hoehn MM, Melvin DY. Parkinsonism: Onset, progression and mortality. Neurology 1967; 17: 427-442.

7. Mahieux F, Michelet D, Manifacier MJ, Boller F, Fetmanian J, Guillard A. Mini-mental, Parkinson: First validation study of a new bedside test constructed for Parkinson's disease. Behavioral Neurol 1995; 8: 15-22.

8. Mattis S. Dementia rating scale. Psychological Assessment Resources, Odesa, Florida, USA 1988.

9. Yesavage JA, Brink TL. Development and validation for a geriatric depression screening scale. A preliminary report. J Psychiatr Res 1983; 17: 7-49.
10. Martinez-Martin P, Frades-Payo B, Rodriguez-Blazquez C, Forjaz MJ, de Pedro-Cuesta J. Psychometric attributes of Scales for Outcomes in Parkinson's Disease-Cognition (SCOPA-Cog), Castilian language. Revista de neurologia 2008; 47: 337-343.

11. Pagonabarraga J, Kulisevsky. Cognitive impairment and dementia in Parkinson's disease. Neurobiol Dis 2012; 46: 590-596.

\section{*Correspondence to}

Hurtado-González CA

School of Psychology

Coperativa University of Colombia in Cali

Cali Branch Campus

Colombia

Email: carlos.hurtadog@campusucc.edu.co 